\title{
Study Tries to Measure and Compare Stress and Job Satisfaction between Surgeons and Lawyers of Sanandaj
}

\author{
Modabber Arasteh $^{1 *}$ and Seyedeh Asrin Seyedoshohadaei ${ }^{2}$ \\ 'Associate Professor of Psychiatry, Department of Psychiatry, Kurdistan University of Medical Sciences, Sanandaj, Iran; \\ Asrin1360@yahoo.co.uk \\ ${ }^{2}$ Assistant Professor of Psychiatry, Kurdistan University of Medical Sciences, Sanandaj, Iran
}

\begin{abstract}
Background and Purpose: Stress is a complex of none specific reactions of an organism to an coping request. Job satisfaction is how happy you are when you are at work Thiel study tries to measure and compare stress and job satisfaction between surgeons and lawyers of sanandaj. Method: It was a survey on 44 surgeons working in sanandaj university hospitals and 49 lawyers of sanandaj bar association which performed by enumeration and with standard questionnaire of "stress" Ramezan zadeh and "job satisfaction Kajbaf. and analysed by Spss 20 and t-test and "exact fisher exam. Findings: In our study lawyer's stress was more than the sugeon's (p:0.01) but their job satisfaction was the same (p:0.35). there were no relationship between age, sex, marriage state and nativity sate with stress and job satisfaction $(\mathrm{p}<0.05)$ But there was statistical relativity between interest in job and stress (p:0.05) which there was not with job satisfaction (p:0.8). There was straight correlation between achievement and job satisfaction, invert correlation between achievement and stress and straight correlation between stress and job satisfaction. Conclusion: This study can prove that there are many factors affecting job satisfaction and stress is only one of them so that lawyers with more stress and less achievement, had the same job satisfaction as the surgeons.
\end{abstract}

Keywords: Stress, Job Satisfaction, Surgeons, Lawyers

\section{Introduction}

The US Bureau of Information has argued that healthcarerelated careers are at the highest levels of occupational injuries among jobs ${ }^{18}$. Identifying sections that give surgeons greater stress or less job satisfaction will lead to more accurate planning and more attention to these areas. Different parts of the hospital have their own working conditions and characteristics, including the number of clients, the status of the patients referred, the type of illness, the number of personnel, the status of the colleagues and so on. Accordingly, various variables such as stress and job satisfaction can be different in them. However, the number of studies that compare different parts of the hospitals in full is small, but there are contradictions between them. For example, some studies have shown that nurses in the emergency department are more stressed ${ }^{2}$ and in another study, nurses in the special department tolerated more stress ${ }^{3}$.

Stress means hugging, squeezing and squeezing. In today's medical science, various equations and assumptions are "urgency" and "coercion" relative to stimuli, the excitement about the psychological responses that it creates, the urgency and coercion of the physiological changes resulting from it? ${ }^{7}$. In general, stress is a force that, when applied to a system, causes some significant changes. This term refers to physical, psychological, social and pressure forces. In this case, stress in this sense is a cause and the introduction of some of the disabilities. On the other hand, stress is a type of psychological stress that is caused by a variety of forces with the above-mentioned pressures, and therefore stress in the second sense is a disability (Marzabadei, 2009). Stress and stress may be perceived by people in a different way. Theoreticians have different perspectives on stress and stress. Some have a negative attitude towards

${ }^{*}$ Author for correspondence 
stress; others regard pressure as a positive factor because it prepares them with significant energy to meet external needs ${ }^{7}$.

Job stress can be seen as a combination of stressors and related occupational conditions that most people agree on. In other words, stress is a stress-induced occupation that a certain person is undergoing for a certain job. The study of occupational stress in the context of tomorrow's relationships with the environment is three factors that are the focus of attention, the individual characteristics of the work, the working conditions and the future of their interaction, which plays a determining role in the occurrence of occupational stress. This view is consistent with the Lazarus exchange model. The main symptoms of behavioral dissatisfaction are job absenteeism, job vacancies, work-related accidents and lack of productivity. Other consequences of occupational stress include job dissatisfaction and the abandonment of profession and expertise. Another is that employees are waiting for retirement. Such an organization faces untapped and unmanageable manpower ${ }^{12}$. Biser and Neouman (1978) have identified three categories of symptoms that are manifest in terms of occupational stress, which are psychological, physical, and behavioral symptoms. Psychological symptoms are emotional and cognitive problems that arise from work-related stress. Job dissatisfaction is one of the most common outcomes of occupational stress. A person who is dissatisfied with his or her job, usually with a BA. Mill is willing to delay his job and he does not want to do his job well. See you Other psychological symptoms of stress include: depression, anxiety, frustration, isolation, anger; some of these symptoms are themselves a problem and, as far as possible, they can exacerbate occupational stress ${ }^{17}$.

On the other hand, stress and occupational stress, and on the other hand, surgeons' job dissatisfaction is another issue that affects communities. Studies show that job dissatisfaction is one of the factors affecting nursing careers. One third of UK and Scotland nurses and more than one-fifth of nurses in the United States tend to leave the profession. Research suggests that the impact of nursing shortages will be highest in 20152020. This lack of strength will keep them from reaching the global goals of health systems and professional nurses' dissatisfaction ${ }^{10}$. Nursing unit characteristics and work environment also have a significant effect on job satisfaction ${ }^{5}$.

In a study, nurses working in private hospitals showed higher levels of satisfaction and intention to stay in the current job than public sector nurses ${ }^{1}$. In the study, the pediatric group had the highest job satisfaction, and the surgical and emergency department had the lowest job satisfaction ${ }^{6}$. In another study, the highest satisfaction was obtained in the operating room and the lowest in the internal sector ${ }^{4}$. However, some studies suggest that there is no significant difference in job satisfaction between nurses in different sectors ${ }^{14}$. According to statistics released by the World Health Organization, England, Finland, Scotland and Ireland are at the top of the world in terms of mortality due to heart disease. The rate of mortality from these diseases in the United States, Japan, Austria and Norway has begun for the first time since the beginning of the century, mainly due to the implementation of stress management programs that have recently been introduced in the realm of industry used. Research shows that the work environment and occupational stress can cause mental illness in the workforce or accelerate the process of mental illness. Following a person's occupational experience, the illness is afflicted and disabled (McLean, 2008).

Based on other studies, the impact of occupational stress on mental health and the body of the staff has been emphasized. Based on these studies, it has been determined that the occupational environment and occupational stress have a negative effect on physical and mental health. Beruzeski (1986) based on 18 years of experience and a study of over 2000 patients, the effects of occupational stress are anxiety, fear, insomnia, irritability, fatigue, and disability in concentration and physical illnesses, such as cardiovascular and gastroenterological disorders. Knows Paule \& Pector (2000) emphasized the relationship between occupational stress and cardiovascular disorders. Ringold, et al (2008) reported that a low level of mental health was associated with high rates of job stress and a low level of social support. The aim of this study is to measure the level of stress and job satisfaction and the factors affecting them among surgeons and lawyers in Sanandaj city and compare them with each other.

\section{Research Methodology}

This is a descriptive-analytic study. The statistical population of the study consisted of Sanandaj surgeon (general - women - orthopedic - neurosurgery - urology) as well as the basic members of a justice center member of the city of Sanandaj. The sample size is equal to the statistical population (93 people). The sampling method is census in this study. The method of data collection was as follows. First, in order to get the letter of introduction to the Bar Association of Sanandaj, after referral of the letter and list of the lawyers of the center, I would refer to the lawyer's office, lawyers, and after presenting the letter of 
reference and explaining the principles and The objectives of the plan, 2 standard "Stress" questionnaires with $0.7,0.86$ reliability, and job satisfaction questionnaire (0.73) and reliability (0.89), were distributed. In the case of surgeons, given the possibility of more contact in the hospital, referring to the Behsat and Tohid hospitals, and sometimes the surgeons' office, after the explanation of the principles and goals, two questionnaires were given to the surgeons to complete them if they wished to cooperate. And they were collected after a few days. Data was collected by computer and analyzed by SPSS 20 software, T-test and Fisher's exact test.

\section{Research Findings}

Table 1 shows the relationship between stress and demographic variables in the statistical population studied.

Table 1. Relationship between stress and demographic variables in the studied population

\begin{tabular}{|c|c|c|c|c|c|c|c|c|c|}
\hline \multirow{2}{*}{\multicolumn{2}{|c|}{$\begin{array}{c}\text { Demographic Variables } \\
\text { Man }\end{array}$}} & \multicolumn{2}{|c|}{ Sex } & \multicolumn{2}{|c|}{ Native status } & \multicolumn{2}{|c|}{ Job interest } & \multicolumn{2}{|c|}{ Groups } \\
\hline & & \multirow{2}{*}{$\begin{array}{c}\text { Female } \\
3\end{array}$} & \multirow{2}{*}{$\begin{array}{c}\text { Indigenous } \\
0\end{array}$} & \multirow{2}{*}{$\begin{array}{c}\text { Non- } \\
\text { native }\end{array}$} & \multirow{2}{*}{$\begin{array}{c}\text { Have } \\
2\end{array}$} & \multirow{2}{*}{$\begin{array}{c}\text { Don't have } \\
3\end{array}$} & \multirow{2}{*}{$\begin{array}{c}\text { Surgeon } \\
0\end{array}$} & \multirow{2}{*}{$\begin{array}{c}\text { Lawyer } \\
2\end{array}$} & \multirow[b]{2}{*}{1} \\
\hline \multirow{4}{*}{$\begin{array}{c}\text { Job } \\
\text { Stress }\end{array}$} & Suspicious & & & & & & & & \\
\hline & normal & 39 & 14 & 21 & 23 & 36 & 8 & 28 & 16 \\
\hline & Neurotoxic & 32 & 6 & 22 & 16 & 26 & 12 & 12 & 26 \\
\hline & Intense & 4 & 1 & 2 & 3 & 2 & 3 & 2 & 3 \\
\hline \multicolumn{2}{|r|}{ Total } & 69 & 21 & 46 & 44 & 67 & 23 & 44 & 46 \\
\hline & $\mathbf{X}^{2}$ & \multicolumn{2}{|c|}{2.3} & \multicolumn{2}{|c|}{0.4} & \multicolumn{2}{|c|}{3.8} & \multicolumn{2}{|c|}{8.8} \\
\hline & $\mathbf{P}$ & \multicolumn{2}{|c|}{0.13} & \multicolumn{2}{|c|}{0.4} & \multicolumn{2}{|c|}{0.95} & \multicolumn{2}{|c|}{0.03} \\
\hline
\end{tabular}

Table 2. Relationship between job satisfaction and demographic variables in the studied population

\begin{tabular}{|c|c|c|c|c|c|c|c|c|}
\hline \multirow{2}{*}{$\begin{array}{c}\text { Demographic Variables } \\
\text { Man }\end{array}$} & \multicolumn{2}{|c|}{ Sex } & \multicolumn{2}{c|}{ Native status } & \multicolumn{2}{c|}{ Job interest } & \multicolumn{2}{c|}{ Groups } \\
\cline { 2 - 10 } & Female & Indigenous & $\begin{array}{c}\text { Non } \\
\text {-native }\end{array}$ & Have & $\begin{array}{c}\text { Don't } \\
\text { have }\end{array}$ & Surgeon & Lawyer \\
$\begin{array}{c}\text { Job } \\
\text { Satisfaction }\end{array}$ \\
\cline { 2 - 12 }
\end{tabular}


Table 3. Comparison of stress and job satisfaction in the studied population

\begin{tabular}{|c|c|c|c|c|c|c|}
\hline \multicolumn{2}{|c|}{ Groups } & Number & Mean-SD & $\begin{array}{c}\text { Average difference and } \\
\text { confidence interval (0.95\%) }\end{array}$ & T & P \\
\hline \multirow{2}{*}{ Job Stress } & Surgeon & 44 & $2.4 \pm 10.4$ & $5.4(1.4 \pm 10.1)$ & 2.6 & 0.01 \\
\cline { 2 - 7 } & Lawyer & 49 & $29.1 \pm 10.2$ & & & \\
\hline \multirow{2}{*}{$\begin{array}{c}\text { Job } \\
\text { Satisfaction }\end{array}$} & Surgeon & 44 & $116.5 \pm 21.2$ & & 0.93 & 0.35 \\
\cline { 2 - 5 } & Lawyer & 49 & $120.1 \pm 15.5$ & & & \\
\hline
\end{tabular}

According to Table 1, there is only a statistically significant difference between surgeons and lawyers in terms of stress $(\mathrm{p}$ $<0.05)$.

According to Table 2, there is no statistically significant difference between the level of stress and demographic variables.

In Table 3, the comparison and status of the research variables in two groups of surgeons and lawyer are discussed.

According to the results of Table 3, the degree of stress of lawyers is higher than surgeons $(\mathrm{p}<0.05)$, but there was no significant difference between job satisfaction and lawyers and surgeons.

\section{Discussion and Conclusion}

In this study, the degree of lawyer stress was higher among surgeons but there was no significant difference between job satisfaction. Also, there was a direct correlation between income and stress, reciprocity, income, and job satisfaction, and there was a direct correlation between stress and job satisfaction.

The average score of the surgeons studied is 23.36 (in the normal range). Also, (4.5\%) suspected stress surgeons (63.7\%) had severe stress in normal range and (31.8\%). In a study by Viser et al. (2003) about stress and job satisfaction among Dutch doctors in 2003, 55\% of doctors had severe stress that was more than ours, which could be due to differences in the way of evaluation (type of questionnaire). The existence of strict medical regulations and cultural differences between the two regions. Also, in a study by Ali khan at Karachi Hospital in Pakistan in 2002, it was found that $48 \%$ of doctors had high and high levels of stress, which was almost the same as ours.
In this study, the average score of job satisfaction of surgeons was 116.5 (average job satisfaction). Also, 11.4\% of the surgeons had low job satisfaction, $79.6 \%$ had moderate satisfaction and $9 \%$ had high job satisfaction. In the study of Seyed Shakir et al. in the Bahawalpur Hospital of Pakistan in 2007, $50 \%$ of doctors had low job satisfaction, $40 \%$ satisfaction with midwifery and $10 \%$ of job satisfaction, which, unlike our study, had a high degree of satisfactory satisfaction, was often low in job satisfaction. This difference may be due to worse conditions of living and working in that country, bad economic conditions and social disadvantages. Also, in the study of Ofilli \& Isuzu (2006) about job satisfaction and mental health at the Benin Hospital in Nigeria in 2006, 54\% had low job satisfaction, $35 \%$ had a moderate job satisfaction, and 16\% had high job satisfaction surgeons. Again Unlike our study, the majority of physicians lacked job satisfaction, which may also be due to differences in working and cultural conditions and economic conditions of the country.

In this study, the average stress score of lawyers (29.13) was at the level of Nerotic stress. Also, 2.2\% were suspected stressed (abnormal patin), 34.8\% had normal stress and 63\% had severe stress. In our study, the average salary satisfaction score of lawyers was 120.1 (average job satisfaction). Also, 0\% of lawyers had low job satisfaction, $90 \%$ had moderate job satisfaction and $10 \%$ had high job satisfaction. In a similar study on 2300 American Bar Association members, the results showed that $15 \%$ of lawyers had low job satisfaction, $71.5 \%$ had average job satisfaction and $13.5 \%$ had high job satisfaction (Erick et al., 1984), Study which is similar to the average.

As mentioned above, the average stress score of surgeons is 23.36 (normal stress) and the mean score of stress and total 
(29.13) (in the northeast range), which is more than stress surgeons based on the T-test. The reason for this can be the difference in the type of stress in these two groups, which means that surgeons' stress is often short-lived and limited for short periods of surgery. While stress usually takes a long time, for example, a lawyer may have one or two years to determine the outcome of a case. On the other hand, people associated with a surgeon - the patient and his family. Most ordinary people are members of the community, if the other party is a lawyer and a lawyer who is harder and harder to deal with. On the other hand, the surgeon is more routine than a lawyer, which leads to a slower stress in them. Perhaps the surgeon's income - based on the evidence of the study - and its reciprocal correlation with the amount of stress makes it less stressful for surgeons. The average of job satisfaction is 116.5 and 120.50 lawyers. According to T-test, there is no significant difference between job satisfaction of lawyers and surgeons. This finding can indicate that many parameters, in addition to stress, affect the job satisfaction of a person (social validity, public safety, respect for society and enjoyment of the work of the soul), which causes lawyers with lower income and more stress, Job satisfaction is equal to the surgeon.

In our study, there is no statistically significant correlation between stress and job satisfaction and sex. Also, according to Fisher's exact test, there is no statistically significant relationship between marital status and stress, as well as job satisfaction. In addition, there is not a meaningful statistical relationship between nativeness, stress and Shoah satisfaction. There is no statistically significant relationship between pre-university interest and job satisfaction. But there is a statistically significant relationship between interest before entering the field and stress $(\mathrm{p}<0.05)$. There is a reverse correlation between income and stress; that is, with increasing income, stress is reduced, which indicates the existence of a causal relationship between stress and income. By increasing income and increasing the welfare of life, individual stress decreases or, conversely, by reducing stress, one can work more actively and more effectively and earn more. There is a direct correlation between income and job satisfaction, that is, by increasing the income of job satisfaction of the individual, in which case income as one of the parameters of effective job satisfaction can directly affect it. There is also a reverse correlation between stress and job satisfaction. In other words, with increasing stress, job satisfaction decreases or vice versa. A similar study was made in the study of American bar association lawyers. The reason may be that people with high stress in all aspects of life such as occupation have low satisfaction or that a person's job satisfaction is high as a stress-reducing factor. In either case, there is a cause and effect between the two, but which independent and dependent is dependent on further studies.

\section{References}

1. Abu Al Rub RF, Omari FH, Abu Al Rub AF. The moderating effect of social support on the stress-satisfaction relationship among in Jordanian hospital nurses. Journal of Nursing Management. 2009; 17(7):870-8. https://doi.org/10.1111/j.1365-2834.2009.01007.x. PMID: 19793244.

2. Aghilinejad M, Attarchi M, Golabadi M, Chehregosha $\mathrm{H}$. Comparing job stress level of woman nurses of different units of Iran university hospitals in 2009. Annals of Military and Health Sciences Research. 2010; 8(1):44-8.

3. Amini F, Farahbakhsh K, Nikoozade Kordmirza A. Comparision of life satisfaction and headiness between intensive care and others units. Journal of Nursing Management. 2012; 1(4):12-6.

4. Asghari E, Khaleghdoost Mohammadi T, Kazem Nezhad E. Effective factor on nurses job satisfaction. Gillan Journal of Nurse-Midwifery. 2013; 3(64):1-7.

5. Baernholdt $M$, Mark BA. The nurse work environment, job satisfaction and turnover rates in rural in urban nursing units. Journal of Nursing Management. 2009; 17(8):994-1001. https:// doi.org/10.1111/j.1365-2834.2009.01027.x. PMID: 19941573.

6. Boyle DK, Miller PA, Gajewski BJ, Hart SE, Dunton N. Unit type differences in RN workgroups job satisfaction. Western Journal of Nursing Research. 2006; 28(6):622-40. https://doi. org/10.1177/0193945906289506. PMID: 16946106.

7. Doyle E Christines. Work and organizational Psychology, An Introduction with attitude. III-18 Psychology Press, Taylor and Francis Group 16- . 2003.

8. Erick Dillan, John H Protzy. Job satisfaction among attorneys of American association bur curupian Journal of Social Science. 1984; 14(3):202-7 II)).

9. Jennifer McLean. Job Stress and Job Satisfaction Among Distance Educators, Pennsylvania College of Technology. 2008.

10. Mortazavi S, Meybodi AR. Effect of job satisfaction on turnover the organizational and personal norm breaking behaviors in nurses. Qom University of Medical Sciences Journal. 2013; 17(1):55-60.

11. Ofilli AN, Isuzu MC. Job satisfaction \& psychological health of the doctors of University of Benin Teaching Hospital. J Ciencio. 2006 April/June; 20:74-8.

12. Osipow SH. Job Stress Inventory Manual (professional version). Odessa FT: Psychological Assessment Resources. 2008.

13. Paule E Spector. Industrial and organizational Psychology. Department of Psychology, University of Florida, John Wiley and Sons. 2000.

14. Rouhi G, Asayesh HHR, Abdollahi A. Comparison of nurses job satisfaction and organizations commitments in intensive care 
and general wards of Golestan University of Medical Sciences. Journal of Gorgan Bouyeh Faculty of Nursing \& Midwifery. 2011; $7(2): 23-32$.

15. Sarah Ringold, Cassio Lynm. Richard T Glass. Substance Abuse. JAMA. 2006; 116(11):11-1.

16. Syed Shakir A Ghazali, Ijaz Ahmad Shah. Job satisfaction among doctors working of Teaching Hospital of Bahawalpur, Pakistan. Journal of Ayub Medical College Abbottabad. 2007; 19(3):23-27.

17. Therese A Joiner, Pauline Stanton. Factors Affecting the Job Stress and Job Satisfaction of Australian Nurses, Implications for recruitment and retentions. Timothy Bartram, School of Business, La Trobe University, Senior Lecturer, School of Management, La Trobe University, Australia. 2008.

18. Toubaei SH, Sahraeian A. Burnout and job satisfaction of nurse working in internal, surgery, psychiatry burn and burn wards. Journal of Medical Science Hygiene Services Gonabad. 2005;12(4):40-6. 